\title{
Joana Nolais e o enigma de gênero: uma discussão psicanalítica da transexualidade
}

Viviana Carola Velasco Martinez

Gustavo Angeli

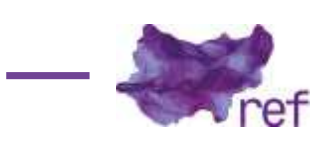

Resumo: O presente artigo aborda a transexualidade, como parte da pluralidade do gênero, dentro da perspectiva da Teoria da Sedução Generalizada, de Jean Laplanche, a partir da qual analisamos a autobiografia de Joana Nolais. Discutimos o gênero como um dos conteúdos das mensagens enigmáticas provenientes do adulto, transmitidas à criança através dos cuidados básicos. Por serem enigmáticas, isto é, da ordem do sexual e, por isso, inconscientes também para o próprio adulto, tais mensagens são traumáticas por excelência, o que exigirá da criança um trabalho de tradução, auxiliada pelo sexo anatômico e a cultura, enquanto organizadores. Consideramos a transexualidade como uma das possíveis traduções do enigma do gênero do adulto efetuadas pela criança desde muito cedo.

Palavras-chove: psicanálise; gênero; transexualidade; teoria da sedução generalizada

Joana Nolais and the Enigma of the Gender: A Psychoanalytic Discussion of Transsexuality Abstract: This article approaches transsexuality as part of the gender plurality, within the perspective of Jean Laplanche's theory of generalized seduction, from the transsexual Joana Nolais autobiography analysis. It discusses the gender as one of the contents from the enigmatic messages which originate from adults, transmited to child through the basic care. For being enigmatic, that is, of the sexual order and, therefore, also unconscious for the adult, these messages are traumatic par excellence, what demands from the child a translation work, assisted by the anatomical sex and the culture, as organizers. Considering the transsexuality as one of the possible trans/ations of the adult gender enigma perfomed by the child since very early.

Keywords: Psychoanalysis; Gender; Transsexuality; Theory of Generalized Seduction

\section{Introdução}

O presente artigo propõe uma discussão sobre a transexualidade feminina, a partir da autobiografia de Joana Nolais (Catherine RIHOT; Joana NOLAIS, 1980). Partimos dos pressupostos de Jean Laplanche, na sua Teoria da Sedução Generalizada - TSG -, sobre a pluralidade e o enigmático do gênero. Trata-se de acompanhar, através da análise e da interpretação, os conflitos de um sujeito e a sua temporalização que exige a transformação radical do seu corpo, do seu sexo, como uma tradução para as mensagens enigmáticas de gênero veiculadas pelo adulto ao cuidar de uma criança.

Jean Laplanche (2006) se refere às mensagens enigmáticas para designar a transmissão de ruídos inconscientes do adulto para o infans. São mensagens enigmáticas porque estão comprometidas com o sexual do próprio adulto - que ele próprio desconhece, porque está recalcado - e que serão inevitavelmente comunicadas à criança através dos cuidados de autoconservação. Trata-se de algo a mais que se comunica, da ordem do polimórfico perverso do adulto, nas ações de cuidado dirigidas à criança e que essa não compreende, pois se trata de um excesso, de um corpo estranho traumatizante e diante do qual nada pode fazer inicialmente, pois seu inconsciente ainda não está constituído, como o do adulto, por exemplo, para poder 
efetuar uma decodificação, ou mesmo um recalcamento. Essa passividade inicial da criança, este desamparo diante do pulsional do adulto, é o que caracteriza a relação assimétrica, que Laplanche (1992) chama de Situação Antropológica Fundamental - SAF, em que um adulto, ao cuidar de uma criança, a seduz porque tem um inconsciente. Em um primeiro tempo a mensagem é apenas inscrita na criança, não há compreensão de absolutamente nada. Somente em um segundo tempo, après-coup, essa mensagem ativada deverá ser traduzida, produzindo simultaneamente uma cisão para compor a tópica freudiana e o recalcamento originário.

Entre as mensagens enigmáticas transmitidas pelo adulto, encontramos as mensagens enigmáticas de gênero, isto é, que o adulto comunica, junto com o que ele sabe sobre o gênero, vinculado ao sexo, e também tudo aquilo que desconhece, aquilo que foi recalcado, sobretudo a pluralidade. Essas mensagens chegam à criança na forma de um excesso, traumático por excelência, diante das quais a criança nada pode fazer inicialmente, até ter constituído seu próprio psiquismo, para, então, poder traduzir e recalcar, e propor constantemente novas traduções ao longo da vida.

É nesse sentido que consideramos a transexualidade como o resultado de uma tradução possível dessas mensagens inconscientes de gênero, veiculadas pelo adulto. Por outro lado, o estudo da transexualidade permite a construção de outros olhares, para além da patologização ou transtorno', sobre o exercício da sexualidade e sua constituição, principalmente se tomamos como pressuposto fundamental a pluralidade do gênero. Nesse sentido, visamos a ampliar a discussão do fenômeno transexual para a origem psíquica da constituição de um indivíduo que está em profundo conflito com seu sexo e seu gênero e que reivindica seu lugar na cultura.

Este artigo nasce de um projeto de pesquisa maior sobre o trauma depois de Freud e se realiza no território da psicanálise extramuros, cuja proposta é expandir a psicanálise para outros campos do saber, além da clínica, para analisar as produções da cultura: "a cultura é feita de psiquismo porque seus criadores são humanos, assim como o sofrimento humano toma forma nas diversas manifestações culturais, desde os sintomas até a arte, passando pela ciência" (Viviana Velasco MARTINEZ, 2003, p. 60).

A História de Joana Transexual (RIHOT; NOLAIS, 1980) é uma autobiografia que nos permite pensar nas origens da transexualidade, para além da patologia ou do transtorno. Joana, ao contar sua história, não apenas relata os acontecimentos, mas os questiona, convidando o leitor a acompanhá-la na elaboração de um novo sentido para cada etapa de sua vida, não sem ingenuidade. Isso nos convida também para a interpretação de sua história.

Dessa forma, fiéis ao método psicanalítico, tomamos a narrativa de Joana Nolais como um caso clínico, fazendo uma leitura de atenção flutuante desse relato, nos deixando levar por uma exigência interpretativa do próprio texto.

Mas como analisar se não estamos diante do sujeito da transferência que conteste, que resista etc.? Como pensar, então, a transferência com um texto? Para Martinez (2003), embora não haja uma relação direta entre o autor e o leitor, não deixa de haver uma transferência a partir do texto que nos instiga à leitura e exige uma interpretação. Mas tratar-se-ia de uma transferência do leitor/analista consigo próprio, o que, para Noël (apud MARTINEZ, 2003), constitui um laço autotransferencial, isto é, o leitor estabelece um laço transferencial consigo mesmo, é a sua própria transferência que viabilizará uma análise do texto.

(...) diferente da transferência do tratamento que envolve dois sujeitos, opera apenas no interior de um sujeito só, como o denominado "transfert de transfert" ou "transferência da transferência" (de Reich, exposto por Lagache e retomado por Laplanche, segundo o autor, p. 181). Trata-se de um processo onde uma parte do sujeito trabalha "sobre" e "com" uma outra parte do mesmo sujeito, com o objetivo de operar uma metabolização perpétua e nisso consiste o trabalho do inconsciente. De alguma maneira, diz o autor, o texto materializa, mantendo as suas peculiaridades específicas, aquilo que o analista encarna durante o tratamento. Porém, o jogo identificatório do tratamento, entre o eu, o recalcado e a pessoa presente do analista, toma um rumo particular explicado pelo autor como um giro, um redemoinho, que não encontra nenhum motivo para parar- e aqui a imagem do laço - porque não há força alguma que possa deter o movimento vertiginoso do tempo que dura o júbilo da leitura. Trata-se, assim, do leitor fascinado, ignorando o que acontece com ele, submerso na sua autotransferência. (MARTINEZ, 2003, p. 190).

A discussão da transexualidade a partir das formulações de Laplanche, sobretudo da pluralidade do gênero, permite lançar um novo olhar sobre o sujeito e sua marca única na assunção da sua sexualidade. Dessa forma, apostamos na criação de um diálogo, a abertura de espaços na academia para este tema, tão do nosso cotidiano.

'O termo utilizado para o fenômeno transexual no DSM-IV era Transtorno de Identidade de Gênero. Atualmente, a transexualidade se configura através do DSM-V como Disforia de Gênero, que se refere à "incongruência entre o gênero experimentado ou expresso e o gênero designado por uma pessoa" (AMERICAN PSYCHIATRIC ASSOCIATION, 2014, p. 451).

2 Revista Estudos Feministas, Florianópolis, 27(1): e48154 


\section{A transexualidade como uma das manifestações da diversidade sexual}

Há, ainda, uma grande confusão na distinção e reconhecimento das características e singularidades da diversidade de gênero. Assim, o sujeito transexual é facilmente confundido com homossexual, intersexual ou travesti. Principalmente no senso comum, e também devido ao forte preconceito, tais divisões ou especificidades desaparecem, como se todo sujeito que não adotasse uma conduta heterossexual fosse, além de imoral ou doente, o estereótipo de um homem afeminado, que desejasse outros homens e que gostaria de se tornar uma mulher - o mesmo vale para a mulher. Entretanto, o gênero, afirma Laplanche (2006), é plural, o que indica que as características de cada gênero revelam um amplo universo com as mais variadas possibilidades de escolhas, identidades e desejos. A transexualidade é, pois, uma dessas possibilidades de organização do gênero.

O termo transexualismo foi adotado em 1953, pelo psiquiatra Harry Benjamin, para designar um distúrbio psíquico no que tange à identidade sexual. O sujeito teria, no caso, a convicção inabalável de pertencer ao sexo oposto. Apesar da origem do termo estar associada a Benjamin, há registros que, em 1949, David Oliver Cauldwell já mencionava o termo Psychopathiatranssexualis, e, em 1923, Magnus Hirschfeld utilizava o termo seelischer Transexualismus.

O termo transexualismo não pode estar associado a uma anomalia genética, ou seja, os estados intersexuais, e nem estar implicada a vontade de se vestir com adereços do outro sexo, nesse caso o travesti. Da mesma forma, a transexualidade não se caracteriza necessariamente por um padrão heterossexual, como sustenta Paulo Roberto Ceccarelli (2003, p. 4): "os transexuais recusam-se obstinadamente ser confundidos com homossexuais. Para eles, sua identidade sexual é decididamente heterossexual, o que é coerente com suas reivindicações", pois a escolha de objeto amoroso pode ser homossexual (Colette CHILAND apud Alain MIJOLLA, 2005). E nem ser confundido com o homossexual, pois este último se caracteriza pela escolha de objeto amoroso do mesmo sexo, e não pela identidade sexual (masculino - feminino). Os transexuais, para Rafael Kalaf Cossi (2011), apresentam uma enorme diversidade no que se refere ao corpo, posturas, práticas sexuais e fantasias.

Assim, encontramos transexuais lésbicas ou gays, que desejam casar e assumir uma postura de submissão ao marido, há também as transexuais feministas e, ainda, as transexuais despolitizadas, por exemplo. "Não há uma única forma de vivenciar a transexualidade, assim como não há uma única forma de viver a masculinidade ou feminilidade" (COSSI, 201 1, p. 100).

O sentimento de pertencimento a outro sexo, a sensação do sujeito habitar um corpo que não se encontra em acordo com sua organização psíquica, as tentativas de se assemelhar e, também, as transformações corporais que permitem uma aparência mais adequada ao psiquismo do individuo não são novidades diante da história da humanidade ou exclusivos da nossa cultura e época (CECCARELLI, 1998).

Em várias culturas, a transexualidade aparece com as suas especificidades. Chiland (2003 apud Milton COSTA, 2011 , p.13) se refere a:

os "hijras" da Índia que praticam a "emasculação artesanal", como uma forma religiosa de culto a uma temível deusa mãe. Lembra ainda dos "berdaches", ameríndios que utilizam vestes femininas e não se consideram nem homens nem mulheres e fariam parte de um terceiro gênero, também com uma função religiosa. Ainda acrescenta o caso de "inuítes", tribos que habitam a região ártica do Canadá, nas quais se considera que as crianças podem mudar de sexo no nascimento, por imposição da mãe, no intuito de que a família possua a mesma quantidade de meninos e meninas. Na adolescência estas crianças veriam restabelecido seu sexo biológico, caso quisessem.

O que temos de efetivamente novo a respeito dessa diversidade de manifestações é, por um lado, a aceitação dessa condição como parte de um processo que se inicia, em 1985, com a retirada da homossexualidade do rol das patologias, assinalando para uma flexibilização em relação à pluralidade do gênero. E, por outro lado, temos a possibilidade atual de transformar $O$ sexo anatômico, graças à sofisticação da medicina e das técnicas cirúrgicas.

Segundo Marcia Aran (2006), as primeiras cirurgias de redesignação sexual ocorreram por volta de 1920 na Dinamarca e na Alemanha. O primeiro transexual operado foi Rudolf, alguns anos depois, o pintor Einar Wegener, aos quarenta anos de idade, que se transforma, através do procedimento cirúrgico, em Lili Elbe. As cirurgias de redesignação sexual, no entanto, só foram amplamente divulgadas em 1952, com o caso de Christine Jorgensen, ex-soldado do exército americano.

De acordo com Ceccarelli (1998), apesar do prefixo trans, na palavra transexualidade, indicar a possibilidade de atravessar, o transexual não consegue trocar de sexo simplesmente. A promessa de uma "mudança de sexo" através da evolução da medicina e das técnicas cirúrgicas é uma mudança apenas de "fachada". O sujeito transexual se vê barrado pela medicina, pois, 
em uma visão restrita ao biológico, não há uma mudança efetiva de sexo, e sim uma troca de atributos de um sexo pela aparência do outro.

Porém, seria apenas o fator anatômico que define o que é ser um homem ou ser uma mulher? Uma transexual deixa de ser mulher pela impossibilidade de ter uma fisiologia feminina? A ciência positivista, conforme aponta Costa (2011), não admite que seja possível tecnicamente mudar de sexo, pois o fenótipo é apenas um dos elementos que compõem a atribuição do sexo, somando-se com a configuração genética e a produção de determinados hormônios. A partir dessa concepção, a transexualidade seria apenas uma fantasia, já que não é possível se tornar uma mulher ou uma mulher por completo, apenas ganhar a aparência de uma. Mas uma mulher ou um homem não podem ser restringidos por um pedaço de carne que sobra ou falta.

De acordo com Berenice Bento (2006), a transexualidade se relaciona diretamente com o saber médico, suas relações de poder e as normativas que partem desse campo para uma atuação e performance no que tange às identidades de gênero. O corpo e as manifestações da sexualidade estão profundamente marcados pelo olhar e o saber médico, dentro de um higienismo atualizado, sofisticado. A autora enfatiza que o saber médico é um dispositivo de controle altamente eficaz, pois, no ato de nomeação, de batismo, realiza uma tarefa aparentemente neutra, naturalizando os fenômenos. Nesse sentido, o médico, como um representante da cultura, é solicitado para corrigir, recortar e adaptar os corpos conforme um padrão estabelecido socialmente.

De acordo com a Classificação Estatística Internacional de Doenças e Problemas Relacionados com a Saúde (CID-10), a transexualidade é definida como "transexualismo" dentro dos "transtornos de identidade sexual" - F64.0 (OMS, 1993, p. 210). O transexual teria como característica o desejo de viver e ser reconhecido como uma pessoa do sexo oposto, bem como o desejo de correção e adequação de seu corpo.

Já o DSM-V (APA, 2014) substitui a palavra transtorno, do DSM-IV (APA, 2003), e adota a "disforia de gênero", isto é, aponta a discrepância entre o gênero experimentado e o gênero designado como ponto central para o diagnóstico, com uma duração de no mínimo seis meses e acompanhado de outros elementos como: "forte desejo de ser tratado como o outro gênero"; "forte convicção de ter os sentimentos e reações típicas do outro gênero"; "forte desejo pelas características primárias e/ou secundárias do outro gênero" (APA, 2014, p. 452-453), entre outros. $O$ diagnóstico também deve considerar o prejuízo social e ocupacional ou em outras atividades da vida cotidiana do indivíduo.

Contudo, mesmo com tal substituição e a eliminação da palavra "transtorno", não se pode dizer que se trata de uma perspectiva menos negativa em torno da ideia de doença mental, ou que se trate de um avanço e uma conquista na luta da despatologizacão da transexualidade. Para Fátima Lima (2014), estamos apenas diante de um deslocamento de termos dentro do manual diagnóstico, e não de um movimento de despatologizacão, tendo em vista que a transexualidade ainda é considerada um sofrimento diante da identidade de gênero. Muitas vezes, atrás do processo transexualizador está a busca por reconhecimento social. Desse ponto de vista, a real necessidade da cirurgia pode ser questionada, se caso socialmente pudesse existir uma diversidade de possibilidades de manifestações do gênero. Entretanto, em alguns casos, o sujeito considera o processo e a cirurgia de transgenitalização de fundamental importância para sua vida e seus projetos (Maria ARAN; Daniela MURTA; Tatiana LIONÇO, 2009).

Se o sofrimento do transexual se encontra, por um lado, no descompasso entre o gênero e o sexo, por outro lado, como aponta Ceccarelli (1998), o transexual, ao buscar um especialista, seja um médico, psicólogo ou psicanalista, não deseja necessariamente lidar com um conflito. Antes de mais nada, o transexual solicita um reconhecimento social, dissemos. O primeiro a diagnosticar o sujeito como transexual é ele próprio. Sendo assim, ao se encontrar com um profissional da saúde, solicita que este o reconheça como mulher ou homem. Não há dúvidas ou incertezas quanto a sua condição transexual, e sim a exigência e a administração de hormônios e a cirurgia de redesignação sexual. Assim, olhar para um transexual e apenas observar os critérios diagnósticos não seria operar uma redução dentro de um modelo biomédico? Qual a história e sofrimento que o sujeito transexual apresenta em relação ao seu corpo? Como se constitui o corpo do transexual?

As discussões em torno da transexualidade estão ainda em torno de ser ou não uma patologia. Na abordagem lacaniana, a transexualidade, para autores como Moustapha Safouan (1979), Marcel Czermak (1991), Catherine Millot (1992) e Henry Frignet (2002), estaria intimamente relacionada a uma estrutura psicótica marcada por uma carência do Nome-do-pai na sua constituição.

Felippe Figueiredo Lattanzio e Paulo de Carvalho Ribeiro (2017, p. 73) analisaram precisamente as teorizações lacanianas que aproximam a transexualidade à psicose e definem, em linhas gerais, quatro eixos principais argumentativos:

(1) considerar a "certeza subjetiva de ser mulher prisioneira num corpo de homem" (Teixeira, 2003, p. 4), fenômeno elementar da psicose; (2) pensar que a transexualidade é uma psicose (a partir da hipótese da forclusão do Nome-do-Pai) na qual se confunde o pênis com o falo; (3) entender que tal condição se dá (ou se acentua) a partir da incidência do discurso da ciência e do

4 Revista Estudos Feministas, Florianópolis, 27(1): e48154 DOI: 10.1590/1806-9584-2019v27n148154 
capitalismo sobre o "envoltório formal" do sintoma psicótico; e (4) postular que na transexualidade o imaginário adquire a mesma importância e significado que apresenta nas outras psicoses.

Nesse sentido, a discussão da transexualidade se situaria exclusivamente dentro dos territórios de uma psicopatologia. Entretanto, o caminho que procuramos trilhar é justamente a passagem de uma concepção patológica para o campo da possibilidade no que se refere à diversidade sexual, ou seja, a possibilidade de um espaço menos rígido ou moralista para as traduções do enigma de gênero. Cabe ressaltar que ao adotarmos esse posicionamento não excluímos ou negamos outras concepções ou a existência de casos que dizem respeito a uma psicopatologia.

Apenas nos situamos diante do vasto território da manifestação da sexualidade humana - no sentido amplo atribuído por Freud (1991 [1910]) de lieben, amar. E isso, do nosso ponto de vista, independe do gênero dual. Este último, como construção cultural, pautada no biológico, ordena, sobretudo, as relações em torno do sexo, de tal maneira que feminino e masculino, ou vagina e pênis, buscariam ou garantiriam a sexualidade genital, adulta, e, assim, estariam a serviço da contenção do polimórfico perverso. Mas nem mesmo o gênero dual seria um antídoto contra o sexual. Tanto que, para Laplanche (2006, p. 1), "O sexual é o resíduo inconsciente do recalcamentosimbolização do gênero pelo sexo" e, por isso mesmo, pode se pensar na possibilidade de ampliar o âmbito da expressão do desejo e da satisfação através da pluralidade do gênero. Desse ponto de vista, talvez tenhamos que repensar se a sexualidade genital, no sentido freudiano, seria necessariamente a única forma adulta de satisfação, sem que isso nos leve de volta ao discurso da perversão.

Por outro lado, se o gênero está direta e unicamente relacionado ao sexo, obviamente a opção por intervenções cirúrgicas ou medicamentosas, conforme aponta Paula Sandrine Machado (2005), submeterão drasticamente o transexual.

\section{A Teoria da Sedução Generalizada e o gênero}

O originário do humano, dentro de uma perspectiva laplancheana, aquilo que para além das contingências deve existir e produzir um sujeito, "é o confronto do recém-nascido, da criança no sentido etimológico do termo, aquele que ainda não fala, com o mundo adulto" (LAPLANCHE, 1992, p.96). A criança necessita de alguém que proporcione os elementos básicos para a manutenção de sua vida, como a comida e a higiene, e também, alguém que provoque nela a manifestação da pulsão. Isso se dá pela subversão do órgão, continua o autor, mas também - e isso é diferente da teoria do apoio de Sigmund Freud (1996a [1905]) - pela sedução que o adulto vai dirigir à criança, pois ao cuidá-la, ele também comunicará inconscientemente a sua sexualidade recalcada. É nesse sentido que o desamparo do recém-nascido não é entendido apenas pela incapacidade de sobreviver por conta própria, mas, também, frente à sexualidade do adulto, que se comunica inevitavelmente em todas as ações dirigidas à criança.

Trata-se de uma relação assimétrica, em que a comunicação da criança se dirige para o adulto com base na autoconservação, mas a do adulto para a criança se rege pela sexualidade, a chamada linguagem da paixão de Sándor Ferenczi (1992 [1933]), que inspira a TSG. É assim que, para Laplanche (1992, p. 105), "há um verdadeiro desencontro entre a via que percorre a criança e a que percorre a mãe".

O originário estaria na situação em que uma criança, desadaptada ao mundo, será cuidada por um adulto "desviante" em relação a sua própria sexualidade. É que a presença da criança, afirma o autor, excita a sexualidade polimórfica perversa do adulto, havendo nessa relação uma "balança desigual", pois se a criança solicita ternura e amparo, o adulto, por sua vez, oferece a sexualidade, seu inconsciente, junto com as suas ações de cuidado. Trata-se da sedução do adulto que nos leva à proposta crucial da Teoria da Sedução Generalizada.

O aspecto traumatizante seria justamente o transbordamento do inconsciente da sexualidade do adulto para a criança. O adulto, através dos cuidados básicos, marca o recémnascido com significantes enigmáticos, ou seja, mensagens provenientes de seu inconsciente e enigmáticas pelo fato do próprio adulto desconhecer seu significado.

Será precisamente o enigmático das mensagens, comunicadas pelo adulto, que como corpo estranho impelirá a criança a iniciar um trabalho de tradução na tentativa de elaborar esse excesso. Ao trabalho de tradução, Laplanche (1992) também atribui, como no trauma, uma temporalidade retroativa em dois tempos. Em um primeiro momento, o da inscrição da mensagem, ela é indecifrável para a criança. Será somente num segundo tempo, après-coup, que efetivamente se iniciará o trabalho de tradução do enigma. Obviamente que, sem um inconsciente, a tradução será feita precária e parcialmente, graças ao auxílio da tradução dos próprios adultos, também comunicada, junto com o excesso. Os restos não traduzidos constituirão o inconsciente, a tópica freudiana e as defesas.

Essas mensagens enigmáticas suscitam um trabalho de domínio e de simbolização difícil, para não dizer impossível, que necessariamente deixa para trás restos inconscientes, fueros, dizia Freud, a que chamamos de "objetos-fontes" da pulsão. (LAPLANCHE, 1992, p. 138). 
É dessa maneira que a tradução se torna um trabalho constante e incessante no psiquismo, junto com os processos de destradução e retradução, pois "o ser humano é e não para de ser um ser auto-tradutivo e auto-teorizante" (LAPLANCHE, 1992, p. 139). É esse processo que marca a temporalização do ser humano e o acompanhará a vida toda, a fim de possibilitar uma melhor versão de si, e de um novo olhar menos opressor e angustiante para a própria história, a partir da tradução do enigma proveniente do outro (LAPLANCHE, 1996).

Entre as mensagens que o adulto comunica à criança, temos as mensagens enigmáticas de gênero. Quando um adulto, afirma Laplanche (1996), atribui para uma criança seu gênero, ao mesmo tempo, transmite suas próprias dúvidas em relação ao que é um homem ou uma mulher. Portanto, as mensagens enigmáticas de gênero carregam os sonhos e as expectativas conscientes do adulto em relação à criança, como também os conteúdos inconscientes, o polimórfico perverso, conflitos e fantasmas. Mesmo que o adulto tenha uma explicação consciente sobre o que é um homem ou uma mulher, a partir da diferença do sexo anatômico e das determinações culturais, essa tradução não está livre dos conteúdos conflitivos.

Mas, continua o autor, não se trata simplesmente de uma atribuição de gênero, e sim de uma prescrição de gênero, pois há um verdadeiro bombardeamento de mensagens prescritivas por parte dos pais em relação ao gênero da criança.

A esse respeito, Viviana Velasco Martinez e Ivy Semiguem Freitas Souza (2014, p. 176-177) citam este elucidativo trecho de William Money e Anke Ehrhardt, que aqui transcrevemos:

\begin{abstract}
Os pais aguardam durante nove meses para ver se a mãe dá a luz a um menino ou uma menina. Se sentem incapazes de influenciar sobre o que a natureza ordena [...] simplesmente estão esperando também o primeiro sinal sobre como devem comportar-se com o recémnascido. Não obstante, quando percebem a forma dos genitais externos, eles colocam em movimento uma cadeia de comunicação. É uma menina! É um menino! Essa comunicação coloca, por sua vez, em movimento, uma cadeia de respostas sexualmente dismorfa, começando pelas cores rosa e azul do berço e da roupa do bebê, o uso de pronomes e a escolha de um nome que será transmitida de pessoa a pessoa para abarcar todas aquelas com que o indivíduo se encontre, dia após dia, ano após ano, desde o nascimento até a morte.
\end{abstract}

Podemos supor que essa prescrição é o resultado do recalcamento do que seria considerado por Laplanche (2006) a pluralidade do gênero, sentida como perigosa pelo meio social. "O gênero é plural. Pode ser duplo, como masculino-feminino, mas não o é por natureza. Muitas vezes é plural, como na história das línguas e na evolução social" (p. 1). Assim, o gênero prescrito pelos pais, masculino ou feminino, serviria também para conter o sexual que, supostamente, estaria atrelado à pluralidade do gênero. Contudo, mesmo que a prescrição do gênero seja feita no plano pré-consciente/consciente, isso não impede que, ao mesmo tempo, o adulto comunique enigmaticamente seus próprios conflitos em torno do sexual, que resulta precisamente, afirma o autor, do recalcamento do gênero pelo sexo.

O interessante é que, nesse processo, e um pouco mais tarde, o reconhecimento do sexo anatômico, que é dual, confirmará para a criança a prescrição do gênero, mas não a poupará de ter que traduzir tudo aquilo ambíguo e excessivo do sexual comunicado pelos pais. O sexo, dessa forma, impõe a binaridade ao sujeito, um recurso de tradução precisamente para recalcar a pluralidade do gênero - toda e qualquer variedade e diversidade de gênero que se contrapõe ao sexo será recalcada -, e o resto da tradução, o resíduo interno, constituirá o sexual-pulsional inconsciente (Christopher DEJOURS, 2006).

Dessa forma, o gênero se constituiria na criança até o primeiro ano de vida, e a constatação da diferença anatômica até o terceiro ano. A criança reconhece em um primeiro momento a distinção de gênero, para depois reconhecer a diferença dos sexos (LAPLANCHE, 2006).

O sexo, então, impõe uma tradução ao sujeito e é esse trabalho que fixa, organiza e normatiza o gênero (Laplanche, 2007). Entretanto, por não dispor de meios, a simbolização dos enigmas das crianças é sempre incompleta, gerando restos que, por sua vez, constituirão o seu sexual pulsional, seus próprios fantasmas, o seu inconsciente, como vimos. Em outras palavras, a criança, que teve um determinado gênero atribuído, tentará dar contornos para a sua pluralidade enigmática de acordo com seu sexo anatômico e com aquilo que sua pequena sociedade permite e, consciente e inconscientemente, coloca como parâmetro. (MARTINEZ; SOUZA, 2014, p. 180).

Apesar do sexo e da cultura possibilitarem a tradução - uma ordenação do sexual e do enigma do gênero -, também limitam as expressões da pluralidade de gênero, dentro do binarismo masculino e feminino. O homem deve corresponder ao masculino, e a mulher ao feminino. Não há espaço para as mais variadas manifestações ou expressões da sexualidade, tudo isso deverá ser contido.

Nesse sentido, apesar da cirurgia de redesignação sexual visar à passagem do transexual dentro da dualidade homem/mulher, a transexualidade ainda pode ser compreendida como uma possibilidade de tradução do enigma de gênero que contesta a referência exclusiva do sexo anatômico. Busca, antes, um reconhecimento e espaço de existência social, uma possibilidade 
de ampliar as manifestações da pluralidade do gênero. Vejamos a autobiografia de Joana (RIHOT; NOLAIS, 1980), as singularidades e especificidades de sua transexualidade e as constantes traduções, destraduções e retraduções que realiza em torno do enigma de gênero, uma volta do recalcado da cultura.

\section{De João à Joana Nolais: traduções, destraduções e retraduções do enigma de gênero}

Partimos do pressuposto que o relato autobiográfico de Joana, como toda escrita, é o resultado de um trabalho de tradução das mensagens enigmáticas. É esta a leitura que propomos, a nossa leitura/interpretação das traduções efetuadas por Joana.

Para Laplanche (1996), a criação de uma obra literária é uma possibilidade de minimizar o sofrimento, é um processo de temporalização, uma construção, après-coup, de um olhar menos opressor e angustiante para a própria história.

É na trama de traduções-destraduções-retraduções que, possivelmente, se constrói a narrativa. Processo esse que não se dá sem dificuldades, pois, quando uma tradução antiga é desfeita, o afeto se desliga da representação e se tem a angústia. Assim, tecer e retecer as próprias vivências, seja na escrita, na música, na pintura ou em uma análise, não se faz sem dores, mas possibilita em algum nível que o sujeito possa tecer uma nova representação de si mesmo, que comporte o que ele foi antes do trauma, o que ele é e o que projeta para si mesmo no futuro. (Mara Geise RODRIGUES; Viviana Carola Velasco MARTINEZ, 2014, p. 867).

Esta é a história de Joana, uma história sobre ser mulher, quando se nasce em um corpo masculino. Uma autobiografia que percorre os caminhos difíceis da tradução do enigmático, diante do recalcamento feroz que a cultura opera sobre a pluralidade do gênero.

Como tantas outras autobiografias, objetiva, também, retirar a transexualidade do anonimato, do submundo e da monstruosidade, e criar um espaço para existir e ser reconhecida socialmente, para além dos estereótipos sociais do masculino e feminino. Trata-se de uma possibilidade de tornar pública, visível, acessível uma das manifestações da pluralidade do gênero.

Joana Nolais percorreu um caminho árduo para ser ela mesma. "Uma história tão louca para um personagem tão normal. Tanto sofrimento e esforço para chegar à sua verdade" (RIHOT; NOLAIS, 1980, p. 10). Interrogada pelo seu enigma, Joana não só se transforma em uma mulher como uma tradução possível do enigmático do gênero -, mas decide, aos sessenta e quatro anos de idade, escrever a sua história, propondo para si mesma, com o efeito do tempo, historicizar-se, e essa é também uma forma de tradução do enigma proveniente do outro.

A História de Joana Transexual (RIHOT; NOLAIS, 1980) foi escrita em conjunto com a jornalista Catherine Rihot, pois Joana não era escritora e tinha dificuldades em organizar suas ideias. Deixemos que a própria Joana se apresente.

Eu sou Joana. Tenho sessenta e quatro anos, um metro e 66 centímetros, sou loura, quase sempre estou de calças compridas e camisa, porque acho mais prático; com a vida que eu vivi, sou independente, gosto de estar livre, de ter liberdade para os meus movimentos. Porém, algumas vezes, uso costumes, costumes de tuide, saias de pregas, tipo clássico. É o que está de acordo com meus gostos e com o meu temperamento. Uso pouca maquilagem: um pouco de pó de arroz, um pouco de base, quase nada de batom. É ainda assim que eu me vejo, é o que convém ao meu estilo, e não faço maiores concessões. Sou respeitada nas lojas, ninguém passa na minha frente: vê-se que sou uma mulher que sabe o que quer. (p. 15).

Apesar de ser Joana quem narra sua própria história - é ela quem "deitamos no divã" -, manteremos seu nome de batismo, masculino², João Eugênio Maurício, até o momento da sua transformação total, apenas para que o leitor se oriente.

Sua história é narrada de forma cronológica: a infância, juventude, o trabalho, casamento e a aposentadoria; contudo, aqui, apresentamos recortes dessa história, que estão em torno da sedução e transmissão de mensagens enigmáticas de gênero, assim como a sua tradução. 0 primeiro recorte se refere à relação intensa e excessiva de João com sua mãe. O segundo recorte diz respeito ao período e aos efeitos da vivência no colégio interno. Já o terceiro recorte marca a saída do pai e a entrada de um segundo homem na família, o padrasto. Por último, temos a morte da mãe e o início das transformações de João em Joana.

\section{A fusão com a mãe: pureza e beleza}

Sobre a sua infância e a mãe, João descreve uma relação intensa e excessiva. Mãe e filho são inseparáveis, não parecendo existir diferença entre um e outro.

${ }^{2}$ A opção de manter o nome original da personagem, João, até o nascimento de Joana, com a cirurgia de redesignação sexual, não está pautada em uma concepção reducionista do gênero ao sexo anatômico, e sim em um processo de amadurecimento do próprio João, que decide se assumir como mulher. 
Nunca pensei separar-me de minha mãe. Não cabia dentro dos meus pensamentos, já que eu achava, e achei, até que o impossível aconteceu, justamente, que eu e ela éramos inseparáveis. Antes dos nove anos, nunca me fiz essa pergunta de saber quem eu era, nem a que sexo eu pertencia. Eu pertencia a um contexto, a um conjunto, que era minha mãe e eu. (p. 22).

A descrição da relação com sua mãe não é apenas a de uma proximidade física, para João, a simples separação dos corpos não é o suficiente para a existência de dois sujeitos, há uma intensa união psíquica, os dois formavam um único indivíduo. Logo João era sua mãe, e sua mãe era João, não havia diferença. Este era o lado positivo do mundo, a vida, a beleza e a pureza. "Como podia eu, pois, desejar ser um dia como meu pai? Ela me dava tudo, e por outro lado, eu era seu refúgio. Esse estado de coisas, por minha parte, poderia ter durado para sempre" (p. 25).

Uma cena descrita por João, sobre o carinho e o cuidado que sua mãe lhe dedicava, nos aproxima um pouco dessa relação.

Parecia-me evidente que minha mãe tinha tanta necessidade de mim como eu dela. Ela me levava para a cama de noite, quando meu pai não estava ou não tinha ainda chegado. Eu adorava me deitar na cama com ela. Ela era linda e tinha cheiro bom, um cheiro especial de mulher. Me apertava contra ela na cama de casal, com os dedos me acariciava as sobrancelhas, era tão doce. Eu lhe dizia bobagens, palavras que não tinham sentido - palavras de amor. Ela me respondia. Nós éramos um refúgio um para o outro. Lembro-me que ela me chamava sua filhinha. Isso nunca me impressionou, ou me pareceu fora de lugar. Eu era aquilo que ela dizia que eu era. (p. 22).

O caráter incestuoso está presente em quase todos os elementos: o quarto do casal, a cama, o lugar do pai ausente, a proximidade e os toques da mãe, o cheiro da mãe. Contudo, nessa cena, tão obviamente sedutora, não necessariamente encontramos a sedução materna, esse algo a mais que se comunica inconscientemente e que tem um efeito traumático. Talvez nem possamos identificá-la, pois o texto de João/Joana é o resultado de traduções e recalcamentos que nos distanciam do originário e, sobretudo, porque é da ordem do inconsciente, do inacessível.

João se entrega sem palavras, ou palavras sem sentido, ao amor da mãe. É que essas poucas palavras dão conta de corresponder ao amor da mãe. Quem ama deve cuidar. O contato e a aproximação, as brincadeiras, as carícias são, para João, da ordem do cuidado e da ternura. Mas por que ela o chama de filhinha? Desejaria que João fosse uma menina? Por quê? O que a mãe comunica da sua própria sexualidade, mobilizada pela presença de João, que deseja transformá-lo em menina?

Ela nunca me disse ter pena de eu ser um menino, e que teria preferido que eu fosse uma menina. Não, nada nesse sentido; não me lembro de que ela falasse de menino, não sei. Mas talvez tenha falado. Diz-se às vezes: "Oh, que lindo menininho!" Parece que eu fui uma criança linda. Não sei. Será que realmente não se falava nisso? Será que eu quis esquecer? Farei eu o possível para não entender, porque não era assunto meu, não era comigo? (p. 22).

João também se vestia, algumas vezes, com o sutiã, calça e sapatos da mãe, sem sentir isso como um ato de transgressão do gênero, pois a tradução deste tipo de mensagens sempre será feito après-coup, isto é, num segundo tempo.

Tudo o que pertencia à mãe era belo, João queria ser como a mãe. A mãe não impedia e ria ao ver seu filho se vestir com seus acessórios femininos.

Já a relação com o pai, descrita por João, está marcada pela violência e indiferença, pois se tratava de um homem frequentador assíduo dos bares, alcoolista, que quando chegava a casa batia em sua mulher. Essa situação provavelmente leva a mãe à traição de ambos, podemos dizer, do pai e do próprio João, pois o que parecia impossível ou inimaginável acontece... A padaria da família tinha um empregado, ex-marinheiro, com quem, João um dia teve a impressão, sua mãe (também) se deitava. Apesar de ser fato corriqueiro imaginar que uma mulher desesperada, com um marido alcoolista, pudesse procurar outro homem, para João foi uma descoberta terrível: ele não era o único apoio de sua mãe.

É nessa época que a mãe decide enviá-lo para um colégio interno, causando-lhe uma grande decepção amorosa. João estava despreparado para renunciar ao corpo da mãe, não foi um acordo, ele se sente abandonado, desamparado e profundamente só. Ele deve virar um homem, é com esse objetivo que João supõe ter sido enviado para um colégio interno. O que não deixa de ser uma tradução bem interessante não só da sedução materna, mas do abandono.

Mas o que podemos dizer com isso da sedução materna? Por um lado, chamá-lo de filhinha e, mais adiante, trocá-lo por um homem de verdade e, ainda, mandá-lo para um colégio interno para que, por sua vez, se transforme também num homem de verdade - parece contraditório. Talvez faça algum sentido se considerarmos que o que está em pauta é o fato de a mãe tomar João como objeto da satisfação polimórfica perversa, motivo pelo qual desapareceria inclusive a ordenação de gênero. Assim, João, que se chama também Eugênio Maurício, como que confirmando através de três nomes o seu gênero masculino, é simplesmente transformado em objeto de desejo pela mãe,

8 Revista Estudos Feministas, Florianópolis, 27(1): e48154 DOI: $10.1590 / 1806-9584-2019 v 27 n 148154$ 
para além de ser filhinho ou filhinha, para além de ser homem ou mulher. É essa a sedução originária, que marca a assimetria adulto infans, em que se implantam os enigmas do gênero, afirma Laplanche (2006), na atribuição de gênero à criança, o que não está associado a uma cena em particular ou focal, mas produz algo traumático e um inconsciente na criança.

E talvez a decepção de João não esteja tanto no fato da mãe ter um amante, mas por ter sido seduzido e abandonado. Abandonado como objeto de satisfação pulsional.

Não é por acaso que João, veremos mais adiante, ingressa na Marinha.

\section{Ser homem? O colégio interno}

O colégio interno provocou não só a separação do corpo materno, mas também impôs o reconhecimento que João era diferente de sua mãe. Ao mesmo tempo, o colégio é tido por João como uma prisão, prisão entre os meninos, e também, no seu próprio corpo. Foram os meninos, segundo ele, que tornaram clara a diferenciação dos sexos. Talvez fosse por isso que João os detestava, e, ainda, porque todos eles eram testemunhas do abandono materno e, sobretudo, da perda da fonte de satisfação, o corpo da mãe. Eram estranhos que estavam entre ele e sua mãe, assim como o amante da mãe, um homem mais forte e viril: é o corpo masculino que o assombra:

Esta parte de mim mesmo, essa coisa exterior, eu não a sentia como uma parte de mim, uma parte do meu corpo. Isso não me pertencia. Era uma peça acrescentada por engano. Enquanto os demais rapazes estavam orgulhosos e o exibiam sem cessar, eu dissimulava, apertava entre as minhas coxas para evitar que aparecesse. Sem isto parecia que eu teria um corpo limpo, puro. (p. 54).

Assim, João descobre que é um menino, e seu sexo é descrito como asqueroso, nojento e sujo. Seu sexo, anteriormente recalcado diante da sedução materna, agora o perturba. Como poder ser uma filhinha se é um homem?

\section{Um homem "de verdade" para a mãe}

Por volta de seus catorze anos de idade se concretiza o segundo casamento de sua mãe e demarca um novo tempo para João com o início de uma série de ressignificações que reforçam seu repúdio de ser e se relacionar com os homens.

O novo marido da mãe é confeiteiro e tem dois filhos. A família se estabeleceu em outra cidade e abre um negocio próprio, uma confeitaria. A relação de João com a família de seu padrasto era delicada, com constantes brigas e desavenças, apesar de ser uma segurança para sua mãe. de "viado".

Em uma refeição com a família, João, com quinze anos de idade, é xingado pelo padrasto

Eu não compreendi logo essas palavras: Bicha! Viado sem vergonha! Mulherzinha de merda! ditas por um homem que a cólera deixava roxo, com os olhos esbugalhados. É claro que achei que se tratava de uma ofensa, pelo tom e pelo silêncio que se seguiu. (p. 51).

Ao escutar tais insultos, a mãe de João permanece em silêncio, com sinais de puro nervosismo; o padrasto e a mãe já deveriam ter conversado sobre esse tipo de assunto antes. Interessante que João teve que buscar ajuda de um primo para entender o que seu padrasto havia lhe falado. Fica difícil concordar em tal inocência de João. Talvez porque o enigmático materno prescindisse efetivamente de um reconhecimento de João, tanto da diferença anatômica quanto de gênero. Afinal de contas, um objeto de satisfação é isso, um objeto.

As memórias invadem os pensamentos de João, e as informações do primo permitiram a ressignificação de momentos do que podemos chamar de assédio dos homens e que nada mais são, supomos, que uma continuidade da sedução precoce. Na realidade, seu ódio pelos homens aparece cedo, com o pai. Sabemos que era um homem traumatizado pelos horrores da Primeira Guerra, e, ainda, que manifestava um ódio intenso e silencioso por João, com quem não falava. Alcoolista e violento com a mãe, após espancá-la, numa ocasião, foi confrontado por João, então com oito anos de idade, com uma arma. Um duelo silencioso que termina com a retirada do pai da cena e a manutenção do silencio constante. Por outro lado, temos um padrasto que algo comunica com seus xingamentos e sua cólera. Ao chamá-lo de "bicha, viado e mulherzinha de merda", é inevitável pensar que há em tudo isso uma excitação muito grande e talvez um desejo muito intenso de tomá-lo efetivamente como uma mulherzinha, nem que seja de merda, e penetrálo, novamente desaparecendo as contenções que a clareza do gênero supostamente operaria. Se se é um menino, não pode ser penetrado. Então, a família decide mandá-lo para o colégio interno para que efetivamente vire um homem. Mas, e por outro lado, como virar um homem se a identificação é com a mãe e é tão intensa?

A descoberta que ele provoca o desejo do outro se torna mais clara e perturbadora para João, começa a entender o significado das investidas homossexuais dos colegas mais velhos no 
internato, das quais ele foge. Embora parecesse perdido, supomos que João consegue traduzir algo do enigmático, a começar pelo reconhecimento da diferença anatômica e, portanto, do repúdio das investidas homossexuais e, finalmente, da própria heterossexualidade também. Optará pela pureza como contenção do sexual e, finalmente, optará por se transformar numa mulher celibatária.

Outras cenas são relatadas neste après-coup propiciado pela palavra "viado". A do vigário, muito simpático, querido e refinado, que um dia o convida para um passeio, admiram a natureza, tomam banho no lago e, em dado momento, o homem o acaricia. João foge, assustado, não toca no assunto e não entende o ocorrido. Também se atualiza, de maneira marcante, o assédio de um vizinho monge, muito querido, que o leva para passear, horas de passeio e histórias, até que um dia solicita que João abaixe as calças para acariciá-lo. "A cena ficou vividamente impressa em mim; cada vez que eu revejo desfilar aquelas imagens na minha mente eu sinto um calafrio de desagrado. A partir desse dia minhas ereções me repugnavam cada vez mais" (p. 49). Se podemos supor que, como no caso Dora, algo extremamente prazeroso é transformado em repugnância, podemos supor também que não há inocência em João - como a sua autobiografia expressa - no que diz respeito ao prazer experimentado, embora conflitante. Contudo, podemos pensar que essa inocência declarada tenha sido uma das traduções possíveis diante do excesso do outro. Da mãe, do pai e seus equivalentes (padrasto, vigário, monge...), com seus cuidados e que demandavam muito mais de João, algo terrível, um sacrifício, talvez, uma emasculação?

O passado é recordado e um novo sentido lhe é atribuído diante do presente, como também o passado aponta para uma nova visão do futuro e a participação da sexualidade consciente e inconsciente do outro se destacam nas cenas. Na realidade, tratava-se de meninos que, na escola interna, o tomam como objeto para a sua satisfação, como uma menina, a filhinha. Talvez porque dentre eles João se destacava com seus traços finos e delicados. Talvez, ainda, porque essa ambiguidade do gênero de João atraísse tanto.

João consegue, après-coup, atribuir um sentido para a aproximação e o olhar dos homens sobre ele na infância e, neste momento, revela seu horror em ser homem e seu desprezo pelo masculino, homens que queriam penetrá-lo. Talvez, antes de todos eles, uma mãe que queria penetrá-lo...

No entanto, mais tarde, aos dezoito anos, tentará mesmo "ser um homem": se alista para a Marinha, para ser fuzileiro naval, treinando com os homens e armas mais brutais, geralmente exprisioneiros. Também terá sua primeira experiência sexual, quando passava suas férias na casa da mãe. João diz guardar a lembrança de ter sido seduzido por uma vizinha mais velha, que encomendara um bolo na padaria da família, fazendo questão que ele o entregasse. 0 marido dela não estava em casa, João entra e, nesse momento, a vizinha o aperta contra si:

Ela fez o papel do homem eu da virgem... Considerei o assunto como coisa sem importância, pura formalidade. Fui seduzido sem nojo, e funcionei sem prazer; uma ejaculação normal, orgasmo pobre... Não me lembro de outra sensação nessa aventura. Senti-me um pouco liberado, e pensei: "Enfim, já está". (p. 73).

Enfim, ter tido uma relação sexual ou seu sexo funcionado era uma prova de normalidade, uma vida que oscilava entre o desagradável e o sem prazer, mas era um homem. Por outro lado, podemos apontar uma metonímia muito interessante entre a vizinha, uma mulher mais velha, e a mãe. Ela o levando para sua cama, quando o pai saía, e apertando-o entre suas pernas... Uma cena de amor que se repete. Entretanto, João, nesse momento, tem mais recursos para lidar com a invasão da sexualidade do outro, é um homem formado e se deixa levar pelos prazeres despertados nas mulheres, mesmo que não os usufrua plenamente, pois aí estará sempre a mãe e a confusão entre ser homem, ser mulher, ser filhinha, ser filhinho, ser uma virgem.

\section{Suportar a perda da mãe}

Aos vinte e um anos de idade, João lamenta a perda da mãe: "Com ela, partia a melhor parte de mim mesmo, eu tinha estado impregnado dela. Sua morte me deixava amputado. Dividido, despedaçado, mutilado..." (RIHOT; NOLAIS, 1980, p. 80). E decide adotar efetivamente o gênero masculino, não só a aparência do que a cultura lhe diz ser, mas se entregando à paixão e às mulheres, se deixando invadir no ato sexual pela pureza e beleza do sexo feminino. Fica mais forte, com cabelos curtos, rosto mais quadrado, pescoço mais grosso. Ser um homem para João, nesse momento, parece fácil, pois o mundo é das aparências, bastava ter dinheiro e independência para simular a masculinidade que não existia ou lhe cabia. Nesse mesmo ano da morte da mãe, ele deixa a Marinha e é convocado para a Segunda Guerra Mundial. Foi no final da Guerra que ele conhece sua esposa e adotam sua filha, Catherine.

Françoise, sua esposa, possibilita que João circule dentro do universo feminino, lhe dá acesso e a liberdade para viver de forma sensível e doce ao seu lado. Não lhe cobra a virilidade ou potência masculina, e sim, doçura e amor. Eis uma solução para João, uma solução de 
compromisso, em torno de uma tradução recalcadora do excesso da mãe, dos pais... Assim, encontra uma mulher que o ajuda a dessexualizar a relação, em nome da ternura e a pureza. $O$ contraponto dessa saída estaria precisamente na sua tentativa de se tornar um homem completo ou, pelo menos, manter as aparências de ser um homem. João inicia um tratamento com hormônios masculinos, porém, a depressão e o mal-estar se agravam. O fracasso do tratamento com hormônios masculinos abre o caminho para uma aposta em hormônios femininos e o início da feminilização do corpo de João.

Mais adiante, a aposentadoria e a morte de sua esposa o fazem se decidir pela transformação em Joana. João começa a se experimentar no universo feminino, muda sua voz e assume seus trejeitos afeminados. Para João, era preciso delicadeza e suavidade ao se comunicar. Joana era gestada por João.

Apesar de ser chamada de "senhora" pelos vizinhos, ao olhar no espelho João se detestava.

Passei minha vida evitando olhar meu sexo, e até mesmo tentando camuflá-lo. Eu havia incubado - dava-me conta cada vez mais, a cada dia que passava - a ideia de que eu ia decidir-me a fazer a operação. Enquanto isso, a presença do meu sexo me incomodava como uma pedra no sapato. Já era uma obsessão, uma urgência. Achava aquilo tudo desagradável, feio, anormal mesmo. Esse pouco de carne que eu tinha tolerado toda minha vida acabava por me fazer horror. (p. 148).

Se transformar em mulher, fisicamente em mulher, passa a ser a sua prioridade. Essa seria, pois, uma forma de traduzir, de forma mais integradora, o enigmático do gênero que a decisão de ser um homem não alcançou de forma satisfatória ou douradora. Mas, traduzir o que do enigmático do gênero?

Assim, foi preciso, num ato, retirar um pedaço de si para dar conta do excesso que the habitava, optando por uma castração voluntária. Joana surgiria para fazer parte do lado positivo da vida, o das mulheres, da pureza e da beleza. Pode se aproximar delas sem mais correr o risco de sujá-las ou violentá-las com seu órgão genital, como fazia o pai com sua mãe.

Numa ação radical, João abre uma via para a penetração, mas, também assim, é possível se deixar acariciar pelo feminino, pelas mulheres, pela mãe.

Em 20 de novembro de 1976, João deixa de existir, Joana acorda da operação. Apesar de tubos pelo seu corpo, não sente dor. O primeiro banho depois da cirurgia fez Joana lembrar de seu último banho como homem. Um corpo transformado e tão sonhado.

Água quente e acolhedora como uma volta ao ventre, um novo nascer. Deixei tanto atrás de mim. E tenho hoje a mesma sensação de limpeza, de capricho. Barbeada e depilada, como fiquei para a operação é então mais impressionante ainda. Impressão de ser virgem... Enfim, me pari eu mesma. Acho-me bela, pela primeira vez na vida. E só agora me dou conta até que ponto eu detestava meu corpo antes. Sempre aquela coisa incomodando, aquela desavença comigo mesma, aquela recusa do meu próprio ser. (p. 158).

Quatro anos depois, Joana diz que seus problemas ficaram na sala de cirurgia. A operação é descrita como porta para liberdade, Joana não precisa mais de ninguém. É independente, livre, equilibrada e forte: é mulher.

Ser uma menina, se transformar em uma mulher, de certa forma, transfigurava o edípico das cenas incestuosas de João e sua mãe. Segundo Freud (1996b [1932]), os cuidados maternos e a vinculação entre mãe e filha podem ser mais duradouros, ou são, digamos assim, permitidos por mais tempo.

O incestuoso do constante e excessivo contato entre João e sua mãe são recalcados, por parte da mãe, na medida em que o transforma em uma menina. Já por parte de Joana, temos a tradução do sexual da mãe na radicalidade da castração, na transformação numa menina. Dessa forma, se anula a necessidade da construção de uma barreira entre mãe e filho e a aproximação e as carícias são permitidas e aprovadas. Nesse sentido, entendemos a cirurgia de redesignação sexual como a única forma de João traduzir e se proteger da sedução e do contato com a mãe. Torna-se ela mesma uma mulher como a mãe, pura, limpa, idealizada e dessexualizada, uma mulher sem um homem. João se sacrifica para que a mãe renuncie a todos os homens. João se transforma em Joana e se esforça para ser uma mulher livre e pura.

\section{Considerações finais}

A teoria freudiana em relação à constituição do psiquismo e ao desenvolvimento da sexualidade já havia apontado - e Laplanche avança muito a esse respeito - que tal processo não é natural, que a simples passagem do tempo não promove o desenvolvimento do aparelho psíquico, e ressalta a importância do adulto na constituição do humano e os mais variados caminhos que se fazem necessários para a satisfação que a pulsão exige. Desse ponto de vista, podemos afirmar que não é possível supor que exista apenas um determinado padrão para a satisfação, em que todos se satisfazem da mesma forma e com os mesmos objetos ou presumir que 
diante da complexidade da constituição não possam emergir traços psíquicos diferenciados. As marcas deixadas por um adulto no corpo e no psiquismo de uma criança promoverão caminhos para sua constituição dos mais variados, possíveis e imagináveis. Nesse sentido, apostamos numa maior liberdade para as manifestações da pluralidade do gênero.

De acordo com Ceccarelli (1999), a psicanálise deve se concentrar na investigação e na compreensão da dinâmica das manifestações da diversidade sexual, e não em discussões sobre a normalidade e a patologia de uma expressão da sexualidade. O trabalho do psicanalista é da criação de psicopatologias próprias e singulares para cada sujeito, da escuta do sofrimento, livre de concepções moralistas. Ceccarelli (1999) ressalta que as expressões da sexualidade não devem ser consideradas problemas, e sim soluções diante das transmissões da sexualidade consciente e inconsciente do adulto, ou seja, uma tradução frente ao enigma de gênero. Nesse sentido, o trabalho com a transexualidade e a diversidade sexual ressalta as inúmeras possibilidades de criação e de elaborações diante do que por excelência é o nosso enigma, a sexualidade, inicialmente a do outro e a nossa própria.

Apesar dos desafios da personagem, de uma história emocionante e repleta de situações que evidenciam o sofrimento e o drama de Joana, e de consideramos a transexualidade como uma tradução radical e extrema em relação ao próprio corpo e gênero, ressaltamos a transexualidade como uma possibilidade de tradução diante das mensagens de gênero e a necessidade de um olhar singular para toda história, pois, se Joana fosse criada em uma família mais amorosa ou atenciosa, ainda poderia ser uma transexual. Nesse sentido, como relembra Ceccarelli (1999), assim como Édipo precisou resolver o enigma da Esfinge, somos todos nós convocados a traduzir o enigma da sexualidade que nos habita, tradução ou resposta única e singular.

\section{Referênclas}

AMERICAN PSYCHIATRIC ASSOCIATION. DSM-IV-TR: Manual Diagnóstico e Estatístico de Transtornos Mentais. Porto Alegre: Artes Médicas, 2003.

AMERICAN PSYCHIATRIC ASSOCIATION. DSM-V: Manual Diagnóstico e Estatístico de Transtornos Mentais. Porto Alegre: Artes Médicas, 2014.

ARAN, Marcia. "A transexualidade e a gramática normativa dos sistemas de sexo-gênero". Ágora: Estudos em Teoria Psicanalítica, n. 9, p. 49-63, 2006.

ARAN, Marcia; MURTA, Daniela; LIONÇO, Tatiana. "Transexualidade e saúde pública no Brasil". Ciência \& Saúde Coletiva, Rio de Janeiro, v. 14, n. 4, p. 1141-1149, 2009.

BENTO, Berenice. A reinvenção do corpo: sexualidade e gênero na experiência transexual. Rio de Janeiro: Garamond, 2006.

CECCARELLI, Paulo Roberto. "Transexualismo e identidade sexuada". In: VIVIANI, Alejandro Luis (Org.). Temas da clínica psicanalítica. São Paulo: Experimento, 1998. p. 137-147.

CECCARELLI, Paulo Roberto. "Sexualidade e preconceito". Revista Latinoamericana Psicopatologia Fundamental, v. 3, n. 3, p. 19-37, 1999.

CECCARELLI, Paulo Roberto. "Transexualismo e caminhos da pulsão". Reverso: Revista Círculo Psicanalítico de Minas Gerais, n. 50, p. 37-49, 2003.

COSSI, Rafael Kalaf. Corpo em obra: Contribuições para a clínica psicanalítica do transexualismo. São Paulo: Versos, 2011.

COSTA, Milton. De um sexo ao Outro: uma abordagem psicanalítica sobre a mudança de sexo. 2011 . Dissertação (Mestrado em Psicologia Social) - Programa de Pós-Graduação em Psicologia Social, Universidade Federal do Rio Grande do Sul, Porto Alegre, RS, Brasil.

CZERMAK, Marcel. Paixões do objeto: estudo psicanalítico das psicoses. Porto Alegre: Artes Médicas, 1991.

DEJOURS, Christopher. "Por una teoría psicoanalítica de la diferencia de sexos. Introducción al artículo de Jean Laplanche". Revista Alter, n. 2, p. 55-67, 2006.

FERENCZI, Sándor. "Confusão de língua entre os adultos e a criança". In: FERENCZI, Sándor. Psicanálise IV. São Paulo: Martins Fontes, 1992 [1933]. p. 97-106.

FREUD, Sigmund. "Sobre el psicoanálisis silvestre". In: FREUD, Sigmund. Obras Completas. Buenos Aires: Amorrortu Editores, 1991 [1910]. Vol. XI. 
FREUD, Sigmund. "Três ensaios sobre a teoria da sexualidade". In: FREUD, Sigmund. Edição Standard Brasileira Obras Psicológicas Completas de Sigmund Freud. Rio de Janeiro: Imago, 1996a [1905]. Vol.VII.

FREUD, Sigmund. "Feminilidade - Conferência XXXIII". In: FREUD, Sigmund. Edição Standard Brasileira Obras Psicológicas Completas de Sigmund Freud. Rio de Janeiro: Imago, 1996b [1932]. Vol. XXII.

FRIGNET, Henry. O transexualismo. Rio de Janeiro: Companhia de Freud, 2002.

LAPLANCHE, Jean. Novos fundamentos para a psicanálise. São Paulo: Martins Fontes, 1992.

LAPLANCHE, Jean. "Temporalidad y traducción. Para un retrabajo de la filosofía del tiempo". In: LAPLANCHE, Jean. La prioridad del otro en psicoanálisis. Buenos Aires: Amorrortu, 1996. p. 65-84.

LAPLANCHE, Jean. "El género, el sexo, el sexual". Revista Alter, n. 2, set. 2006. Disponível em: https:// revistaalter.com/revista/el-genero-el-sexo-lo-sexual-2/937/. Acesso em: 14/03/2016.

LATTANZIO, Felippe Figueiredo; RIBEIRO, Paulo de Carvalho. "Transexualidade, psicose e feminilidade originária: entre psicanálise e teoria feminista". Psicologia USP, São Paulo, v. 28, n. 1, p. 72-82, abr. 2017.

LIMA, Fátima. Corpos, gêneros, sexualidades: políticas de subjetivação. Porto Alegre: Rede Unida, 2014.

MACHADO, Paula Sandrine. "O sexo dos anjos: um olhar sobre a anatomia e a produção do sexo (como se fosse) natural”. Cadernos Pagu, v. 24, p. 249-281, jan/jun. 2005.

MARTINEZ, Viviana Carola Velasco. A figura do herói: entre a falta e o excesso - por uma ruptura de campo em tres tempos; a criança e o videogame, o herói mitológico e o homem psicanalítico. 2003. Tese (Doutorado em Psicologia Clínica) - Programa de Estudos Pós-graduados em Psicologia Clínica, Pontifícia Universidade Católica de São Paulo, SP, Brasil.

MARTINEZ, Viviana Carola Velasco; SOUZA, Ivy Semiguem Freitas. "O mito das Amazonas em cena: uma discussão psicanalítica sobre a feminilidade e o gênero". Cadernos de Psicanálise, v. 36, n. 30, p. 171-197, jan/jun. 2014.

MIJOLLA, Alain. Dicionário internacional da psicanálise: conceito, noções, biografias, obras, eventos, instituições. Rio de Janeiro: Imago, 2005.

MILLOT, Catherine. Extrasexo: ensaio sobre o transexualismo. São Paulo: Escuta, 1992.

ORGANIZAÇÃO MUNDIAL DE SAÚDE. Classificação de transtornos mentais e de comportamento da CID-10: descrições clínicas e diretrizes diagnósticas. Porto Alegre: OMS, 1993.

RIHOI, Catherine; NOLAIS, Joana. Joana. História de Joana transexual. Rio de Janeiro: Nórdica, 1980.

RODRIGUES, Geise Mara; MARTINEZ, Viviana Carola Velasco. "A narrativa testemunhal e o enredamento do traumático no psiquismo". Revista Latinoamericana Psicopatologia Fundamental, v. 14, n. 4, p. 858-871, dez. 2014.

SAFOUAN, Moustapha. Estudos sobre o Édipo: introdução a uma teoria do sujeito. Rio de Janeiro: Zahar Editores, 1979.

Viviana Carola Velasco Martinez (iD) 0000-0002-5389-7988

Doutora. É professora do Departamento de Psicologia e coordenadora do Laboratório de Estudos e Pesquisa em Psicanálise e Civilização.

Universidade Estadual de Maringá, Departamento de Psicologia

Avenida Colombo, 5790

87020-900 - Maringá - PR - Brasil

(44) 30113871 secppiuem@gmail.com

vcvmartinez@hotmail.com 
Gustavo Angeli (iD) 0000-0003-1732-1081

Mestre em Psicologia

Centro Universitário de Brusque

Rua Dorval Luz, 123 - Santa Terezinha

$88352-400$ - Brusque - SC, Brasil

(47) 3211-7000-coordenacaopsico@unifebe.edu.br

gustavooangeli@gmail.com

\section{COMO CITAR ESSE ARTIGO DE ACORDO COM AS NORMAS DA REVISTA}

MARTINEZ, Viviana Carola; ANGELI, Gustavo. "Joana Nolais e o enigma de gênero: uma discussão psicanalítica da transexualidade". Revista Estudos Feministas, Florianópolis, v. 27, n. 1, e48154, 2019.

\section{CONTRIBUIÇÃO DE AUTORIA}

Viviana Carola Velasco Martinez - Concepção e elaboração do manuscrito. Análise de dados, Participação ativa da discussão dos resultados, Elaboração do manuscrito, revisão e aprovação da versão final do trabalho.

Gustavo Angeli - Concepção e elaboração do manuscrito. Análise de dados, Participação ativa da discussão dos resultados, Elaboração do manuscrito, revisão e aprovação da versão final do trabalho.

\section{FINANCIAMENTO}

Não se aplica.

\section{CONSENTIMENTO DE USO DE IMAGEM}

Não se aplica

\section{APROVAÇÃO DE COMITÊ DE ÉTICA EM PESQUISA}

Não se aplica

\section{CONFLITO DE INTERESSES}

Não se aplica

\section{LICENÇA DE USO}

Este artigo está licenciado sob a Licença Creative Commons CC-BY. Com essa licença você pode compartilhar, adaptar, criar para qualquer fim, desde que atribua a autoria da obra.

\section{HISTÓRICO}

Recebido em 13/12/2016

Reapresentado em 04/07/2018

Aprovado em 09/08/2018

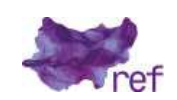

14 Revista Estudos Feministas, Florianópolis, 27(1): e48154 DOI: 10.1590/1806-9584-2019v27n148154 